\title{
The root cause of anxiety during reoperative aortic valve surgery
}

\author{
Luke M. Wiggins, MD, and S. Ram Kumar, MD, PhD, FACS
}

\footnotetext{
From the Division of Cardiac Surgery, Department of Surgery, Keck School of Medicine of the University of Southern California, Los Angeles, Calif; and the Heart Institute, Children's Hospital Los Angeles, Los Angeles, Calif.

Disclosures: Authors have nothing to disclose with regard to commercial support.

Received for publication Jan 22, 2018; accepted for publication Jan 30, 2018; available ahead of print March 9, 2018.

Address for reprints: S. Ram Kumar, MD, PhD, FACS, Children's Hospital, Los Angeles, 4650 Sunset Blvd, Mailstop 66, Los Angeles, CA 90027 (E-mail: rsubramanyan@ chla.usc.edu).

J Thorac Cardiovasc Surg 2018;155:e183-4

$0022-5223 / \$ 36.00$

Copyright (c) 2018 by The American Association for Thoracic Surgery

https://doi.org/10.1016/j.jtcvs.2018.01.052
}

An abnormal aortic root (Figure 1) can result from congenital malformations, such as Shone complex; from aneurysmal disorders, such as Marfan syndrome; or from aortic root infections. Advances in the surgical approach to aortic root replacement have resulted in significant improvement in outcomes. A recent review of aortic root surgeries in the Society of Thoracic Surgeons database reported an overall mortality of $4.6 \%$ for first-time aortic root replacement. ${ }^{1}$ Not infrequently, failure or infection of the prosthetic aortic root necessitates reoperative aortic root replacement. Reoperation on the aortic root is a technically challenging procedure associated with significant increases in morbidity and mortality. Unlike primary aortic root replacement, reoperative root replacement carried an $8.9 \%$ mortality in the Society of Thoracic Surgeons database study. ${ }^{1}$ In centers with focused expertise in aortic root pathology, reoperative aortic root replacement is associated with relatively low operative mortality and perioperative morbidity ${ }^{2}$; however, long-term survival continues to be suboptimal.

In this issue of the Journal, Rowse and colleagues ${ }^{3}$ describe a case of seventh-time sternotomy for replacement of a failing prosthetic aortic valve. At the age 8 their patient underwent aortic root enlargement and replacement, followed by multiple prosthetic valve replacements. A heavily calcified root at this presentation precluded the intended valve or root replacement procedure. Ultimately, Rowse and colleagues ${ }^{3}$ resected the degraded bioprosthetic valve leaflets and placed a mechanical valve within the sewing ring of the old valve. Their "valve-in-valve" approach is a slight modification of previous approaches to a hostile aortic root. As alluded to in this report, these approaches include a "valve-on-valve" technique or unhinging the mechanical valve leaflets to accommodate a new root over the existing prosthetic sewing ring. It is impressive that today's surgical acumen allows us to conceptualize and execute safely such unconventional and heroic interventions when faced with a dire situation in the operating room.

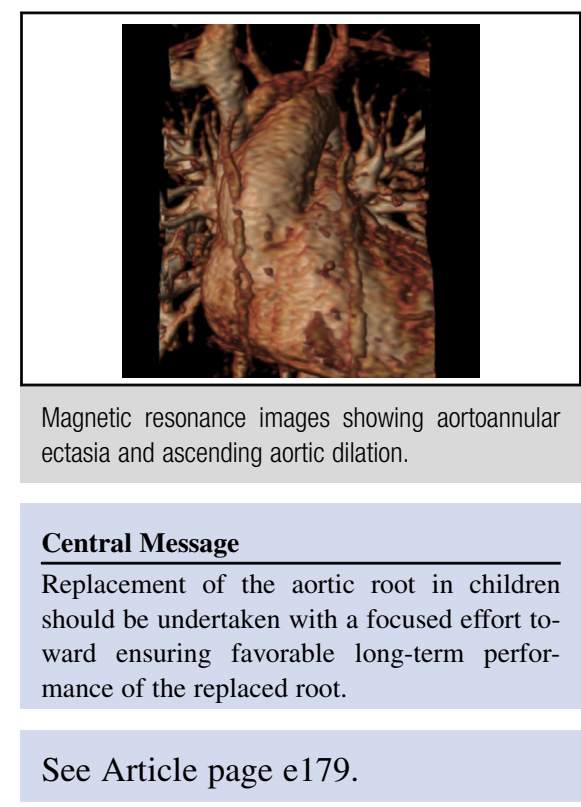

Although the patient in the report had an excellent outcome, one can easily fathom other circumstances in which such an approach might not be feasible. Examples include a small root or a small original valve, such that a new valve inside the old sewing ring would result in patient-prosthetic mismatch. Rowse and colleagues ${ }^{3}$ touch on some of the other potential options. As experience with transcatheter valves continues to improve, the indications for these valves are expanding. The concerns of Rowse and colleagues $^{3}$ regarding long-term viability of these valve-in-valves are legitimate. ${ }^{4}$ In addition, transcatheter valves have not yet been widely used inside preexisting mechanical valves. Another unanswered question is this: When do repeated attempts at palliating a defective heart become one too many? What are the medical and ethical considerations behind pursuing heart transplantation in this subset of patients?

Given the complexities in managing these disease processes, it is imperative that early in the management pathway we choose interventions with more favorable long-term outcomes and reintervention profiles. It is tempting to assume that the use of a mechanical aortic prosthesis provides the most durable long-term result. This has not been borne out in longitudinal analyses. The need for lifelong anticoagulation and the attendant lifestyle modifications, the ongoing hazard for thromboembolic and hemorrhagic events, and the need to upsize the valve to match 

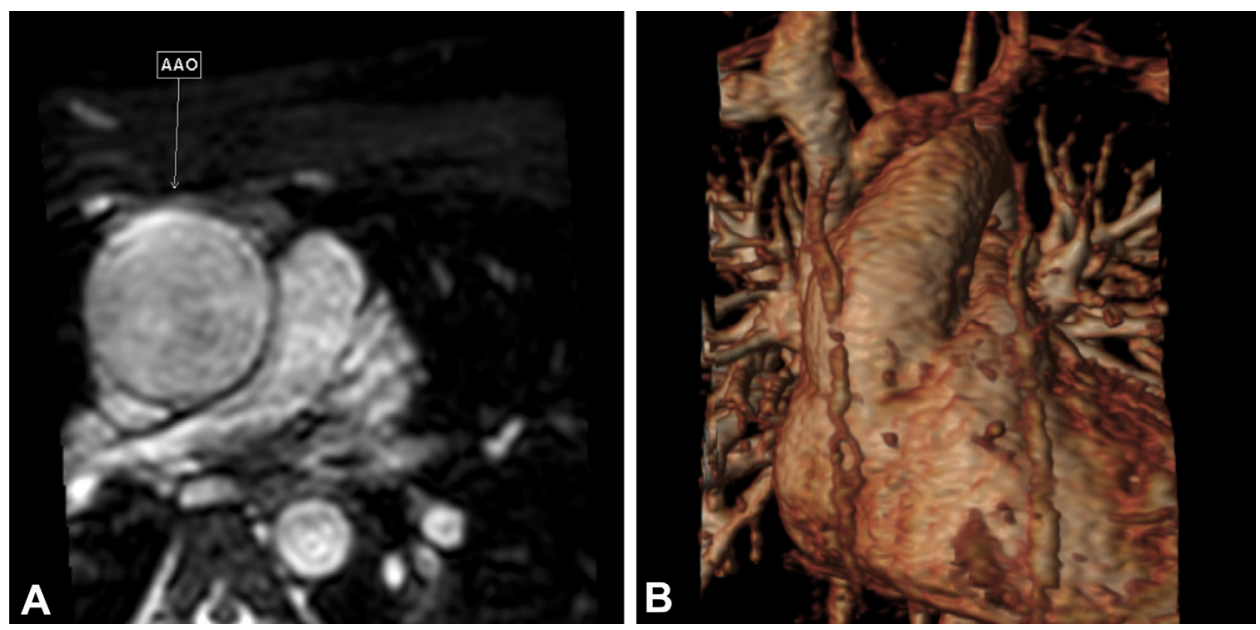

FIGURE 1. Magnetic resonance transverse section image (A) and 3-dimensional reconstruction (B) showing aortoannular ectasia and ascending aortic dilation in a 16-year-old boy. The patient has concomitant aortic valve disease according to echocardiography and is scheduled to undergo an autograft replacement of the aortic root along with ascending aortic replacement. $A A O$, Ascending aorta.

somatic growth in younger children continue to dampen the enthusiasm for the use of mechanical aortic prostheses. Our own preference in an 8-year-old child with an irreparable aortic valve would be to replace the valve with an autograft root (Ross procedure), especially when the root requires enlargement, which can be relatively easily achieved with a concomitant modified Konno procedure. We and others have shown that such an approach is associated with low morbidity and mortality. ${ }^{5,6}$ The autograft valve grows with the patient, and the long-term valve and ventricular functions are excellent, resulting in a very favorable symptom profile. ${ }^{5}$ Freedom from reintervention on the left ventricular outflow tract is about $80 \%$ at 10 years. Technical modifications can further limit root dilation, which is one of the more common reasons for reintervention. When the root does dilate, the root alone can be replaced and the autograft valve successfully spared, further extending the duration of benefits from having an autologous valve in the aortic position. ${ }^{7}$ A recent propensity-matched comparison of the Ross procedure versus mechanical aortic valve replacement confirmed that the Ross procedure has comparable survival and a significantly more favorable clinical profile. $^{8}$ Although the Ross procedure may be a more technically challenging initial procedure, it is well worth the effort if it can prevent the need for multiple reoperations and unconventional procedures to ensure a functional left ventricular outflow tract.

\section{References}

1. Stamou SC, Williams ML, Gunn TM, Hagberg RC, Lobdell KW, Kouchoukos NT. Aortic root surgery in the United States: a report from the Society of Thoracic Surgeons database. J Thorac Cardiovasc Surg. 2015;149:116-22.e4.

2. Garrido-Olivares L, Maganti M, Armstrong S, David TE. Clinical outcomes of aortic root replacement after previous aortic root replacement. J Thoracic Cardiovasc Surg. 2013;146:611-5.

3. Rowse PG, Egbe AC, Said SM. Facile conversion from biologic to mechanical prosthesis: a bailout for a hostile aortic root. J Thoracic Cardiovasc Surg. 2018; 155:e179-81.

4. Dvir D, Webb J, Brecker S, Bleiziffer S, Hildick-Smith D, Colombo A, et al. Transcatheter aortic valve replacement for degenerative bioprosthetic surgical valves: results from the global valve-in-valve registry. Circulation. 2012;126: 2335-44.

5. Bansal N, Kumar SR, Baker CJ, Lemus R, Wells WJ, Starnes VA. Age-related outcomes of the ross procedure over 20 years. Ann Thorac Surg. 2015;99:2077-83; discussion 2084-5.

6. Nelson JS, Pasquali SK, Pratt CN, Yu S, Donohue JE, Loccoh E, et al. Long-term survival and reintervention after the Ross procedure across the pediatric age spectrum. Ann Thorac Surg. 2015;99:2086-94; discussion 2094-5.

7. Kumar SR, Bansal N, Wells WJ, Starnes VA. Outcomes of reintervention on the autograft after Ross procedure. Ann Thorac Surg. 2016;102: 1517-21.

8. Mazine A, David TE, Rao V, Hickey EJ, Christie S, Manlhiot C, et al. Long-term outcomes of the Ross procedure versus mechanical aortic valve replacement: propensity-matched cohort study. Circulation. 2016;134:576-85. 